\title{
Field Performance of a District Central Ground Source Heat Pump System in the US
}

\author{
Piljae Im, PhD
}

\author{
Xiaobing Liu, PhD
}

\author{
Hugh Henderson
}

\begin{abstract}
This case study discusses the field performance of a district central ground source heat pump (GSHP) system installed at Ball State University (BSU) in Muncie, IN., USA. This district GSHP system replaces the existing central steam plant and water-cooled chiller plants and designed to serve 47 major buildings in BSU. The field performance of the GSHP system was analyzed based on measured data from August 2015 through July 2016, construction drawings, maintenance records, personal communications, and construction costs. It was compared with the performance of a baseline scenario - a conventional water-cooled chiller and natural-gas-fired boiler system, both of which meet the minimum energy efficiencies allowed by the American Society of Heating, Refrigerating and Air-Conditioning Engineers (ASHRAE 90.1-2013). The comparison was made to determine source energy savings, energy cost savings, and $\mathrm{CO}_{2}$ emission reductions achieved by the GSHP system. This paper presents the results of the analysis, the lessons learned, and recommendations for improvement in the operation of this district central GSHP system.
\end{abstract}

\section{INTRODUCTION}

High initial costs and a lack of public awareness about ground source heat pump (GSHP) technology are the two major barriers preventing rapid deployment of this energy-saving technology in the United States (Hughes 2008). To tackle these barriers, 26 GSHP projects were competitively selected by the US Department of Energy in 2009 and awarded grants funded by the American Recovery and Reinvestment Act to demonstrate the benefits of GSHP systems and innovative technologies for cost reduction and/or performance improvement. A district central GSHP system that ultimately would replace the existing coal-fired steam boilers and conventional water-cooled chillers on the campus of Ball State University (BSU) in Muncie, IN was one of the 26 selected demonstration projects. This case study evaluates the performance of the demonstrated district central GSHP system based on measured performance data, utility bills, and other relevant information. The evaluated performance metrics include the energy efficiency of the overall GSHP system, electricity usage of all major equipment of the GSHP system, and the achieved benefits (e.g., energy and cost savings) compared with a new conventional HVAC system. This case study also identifies opportunities for improving the operational efficiency of the system.

\section{SITE DESCRIPTION}

Prior to implementing the district GSHP system, 47 major buildings in BSU were served by a central steam plant with 4 coal-fired and 3 natural gas-fired steam boilers. Cooling was provided by 5 water-cooled centrifugal chillers at the District Energy Station South (DESS). Faced with the need to eliminate the coal-fired boilers and aging chillers, BSU considered several options, including circulating fluidized bed coal boilers and improved stack controls. 
Finally, a geothermal system with heat recovery (HR) chillers was selected to meet the simultaneous heating and cooling needs in the campus. Although the district GSHP system has a cost premium compared to other options, it has higher energy savings potential. It was one of major reasons for the final selection.

The implementation of the GSHP system was taken in two phases. Phase 1 included constructing a geothermal field with 1,803 vertical boreholes, as well as a new District Energy Station at the North side of the campus (referred as DESN). This energy station includes two new 2,500 ton two-stage HR chillers connected to the phase 1 geothermal fields (Figure 1). These chillers can simultaneously produce chilled water $\left(\right.$ at $42^{\circ} \mathrm{F}$ or $\left.5.6^{\circ} \mathrm{C}\right)$ and hot water up to $150^{\circ} \mathrm{F}\left(65.6^{\circ} \mathrm{C}\right)$. In Phase 2, the existing conventional chillers in DESS were replaced with other two 2,500 ton $\left(8,750 \mathrm{~kW} \_c l g\right)$ two-stage HR chillers. These chillers are connected to the phase 2 geothermal fields at the south end of the campus. This case study focuses on evaluating the field performance of the GSHP system implemented in phase 1. Buildings in the BSU campus were retrofitted and connected to the district GSHP system gradually over several years. As more buildings were connected to the GSHP system, the heating and cooling loads imposed on DESN increased from year to year. Control and operation of the GSHP systems has been adjusted by the facility operators to improve the performance of the GSHP system.

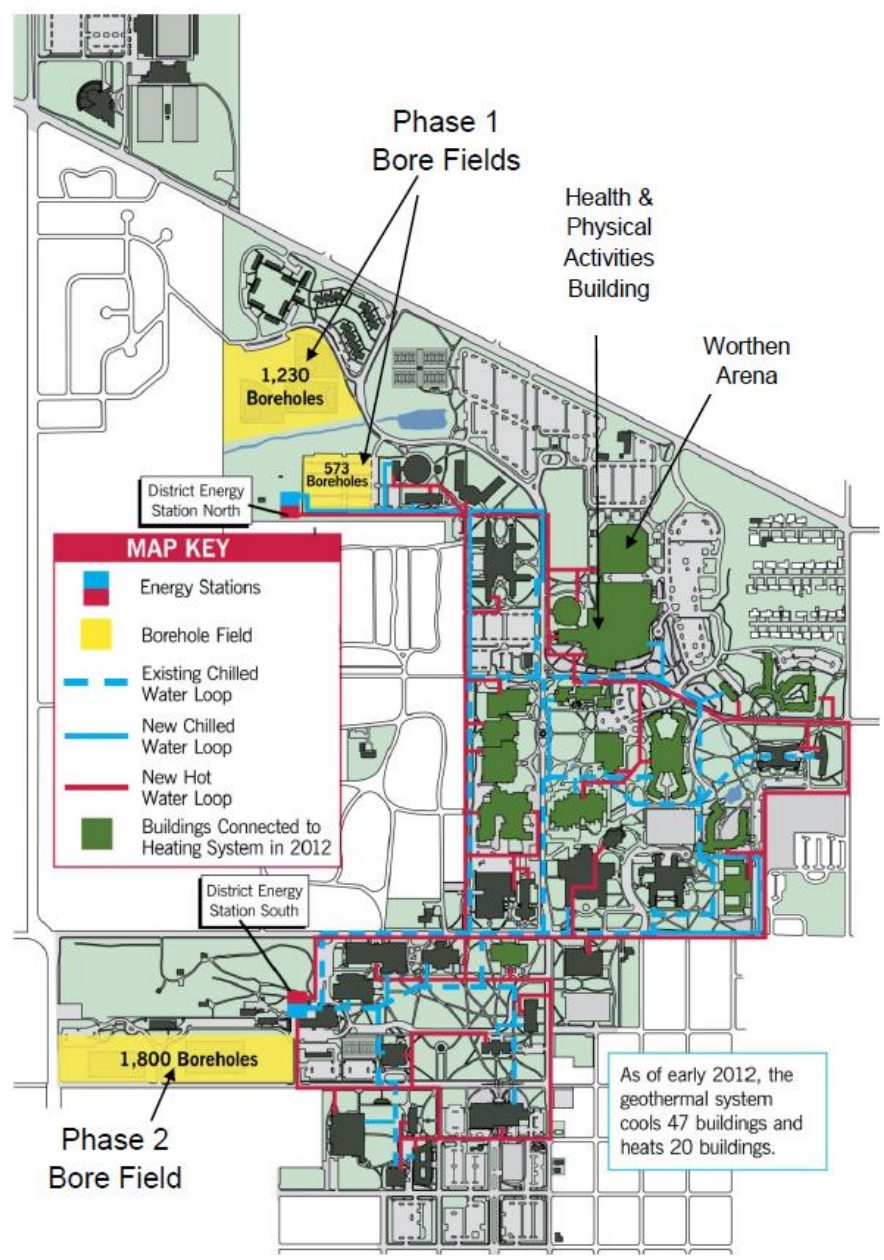

Figure 1. Ball State University campus map showing the energy stations, chilled water and hot water loops, and geothermal borehole fields in Phase 1 and Phase 2 of the district central GSHP system. As shown in this map is the buildings connected to the GSHP system in 2012.

\section{GSHP System Description}


The district GHP system implemented in phase 1 includes two geothermal borehole fields, two HR chillers, three water loops, and a new campus-wide control and monitoring system. All the chillers and pumps are installed in a new building (DESN). Chilled water and hot water are produced by the HP chillers and distributed to buildings in the campus through a chilled water (CHW) loop and a hot water (HW) loop. As of May 2106, 47 buildings are connected to the CHW loop and 30 buildings are connected to the HW loop. Note that there were only 20 buildings connected to the HW loop in 2012. Expansion of the HW loop to serve more buildings is still ongoing.

Geothermal Borehole Fields. Two geothermal borehole fields were constructed during Phase 1 as shown in Figure 1. One borehole field includes 1,230 bores and the other has 573 bores. Each bore is $400 \mathrm{ft}(122 \mathrm{~m})$ deep and the bores are spaced by $15 \mathrm{ft}(4.6 \mathrm{~m})$ between centers. Two 1-inch diameter high density polyethylene (HDPE) Ushape loops filled with water are inserted into each bore, which is then grouted with a mixture of sand, bentonite, and water. All the HDPE pipes are routed into DESN through 5 major circuits that are buried $5 \mathrm{ft}(1.5 \mathrm{~m})$. under the ground. An in-situ ground thermal conductivity test was performed in a borehole at the site. The test result indicated that the effective ground thermal conductivity at the test site is about $1.68 \mathrm{Btu}-\mathrm{hr}^{-1}-\mathrm{ft}^{-1}-\mathrm{F}^{-1}\left(2.9 \mathrm{~W}-\mathrm{m}^{-1}-\mathrm{K}^{-1}\right)$, and the undisturbed ground temperature is about $56^{\circ} \mathrm{F}\left(13.3^{\circ} \mathrm{C}\right)$.

Heat Recovery Chillers. Two 2,500-ton (8,750 kW_clg) HR chillers (CH \#1 and $\mathrm{CH} \# 2)$ are installed in DESN. Figure 2 shows the schematic of the two HR chillers with the associated control valves and pumps. During typical operation, $\mathrm{CH} \# 1$ is run to produce both $\mathrm{HW}$ and $\mathrm{CHW}$. If the HW load is smaller than the available heating capacity, then the HW return temperature starts to rise above the desired set point. The HW return is then directed to the geothermal field (referred as ground loop hereinafter), and water retuning from ground loop is directed back to the condenser of the chiller. This is achieved by opening valves CV-LFW-01 and CV-LFW-03, which connect the ground loop to the condenser side of the chiller. Then control valves CV-CW-01 and CV-CW-03 (for chiller \#1 or CV-CW-05 and CV-CW-07 for chiller \#2) modulate in opposite directions to control the HW return temperature (back to the condenser side of the chiller) at the desired temperature (the set point was $106^{\circ} \mathrm{F}$ or $41.1^{\circ} \mathrm{C}$ ). As the second stage of control, the circulation pumps for the ground loop are staged to maintain HW return temperature at the desired set point. On the other hand, when cooling load is too small, resulting the CHW return temperature drops below a set point, valves CV-LFW-02 and CV-LFW-04 are opened to allow some returned CHW going through the ground loop and then mixing with other returned $\mathrm{CHW}$. These valves are cycled $\mathrm{ON}$ and OFF to increase the $\mathrm{CHW}$ return temperature.

Besides, there are other four chillers in the South Plant (DESS)— two HR chillers ( $\mathrm{CH} \# 3$, and $\mathrm{CH} \# 4)$ are connected

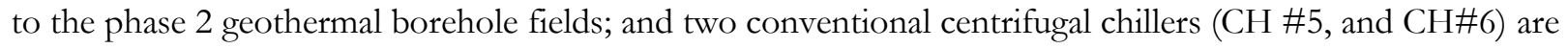
connected to a cooling tower. The six chillers in DESN and DESS are staged to meet the cooling demands in the campus. The two chillers in DESN are used at first stage1. When the cooling demand is larger than the capacity of $\mathrm{CH} \# 1$ and $\mathrm{CH} \# 2$, other chillers will be added on following the sequence of $\mathrm{CH} \# 3$, $\mathrm{CH} \# 4, \mathrm{CH} \# 5$ and $\mathrm{CH} \# 6$.

Pumps. There are three sets of pumps in DESN and each is used for the ground loop, CHW loop, and HW loop, respectively. In addition, the condenser and evaporator sides of each chiller, as well as the cooling tower, have their own dedicated (primary) pumps. Three $350 \mathrm{HP}$ pumps are connected parallelly to distribute CHW throughout the campus, and similarly, three $300 \mathrm{HP}$ pumps are used to distribute HW. When the HW or CHW produced by the chiller excesses the demand, it is circulated through the geothermal borehole field with three in parallelly connected pumps (250 HP each). The dedicated pumps used in condenser and evaporator sides of each chiller, as well as the cooling tower, all have $125 \mathrm{HP}$ power. Each building has its own internal water loops and (tertiary) pumps to extract $\mathrm{CHW}$ and $\mathrm{CW}$ from the main campus-wide $\mathrm{CHW}$ and $\mathrm{CW}$ loop and return it back to the main loop. The tertiary pumps are controlled to maintain a pre-defined temperature difference across the building's internal water loop.

\footnotetext{
${ }^{1}$ Measured data showed that there was not any occasion that both $\mathrm{CH \# 1}$ and $\mathrm{CH \# 2}$ were operated at the same time. While $\mathrm{CH} \# 1$ ran most time, $\mathrm{CH} \# 2$ only ran sporadically.
} 


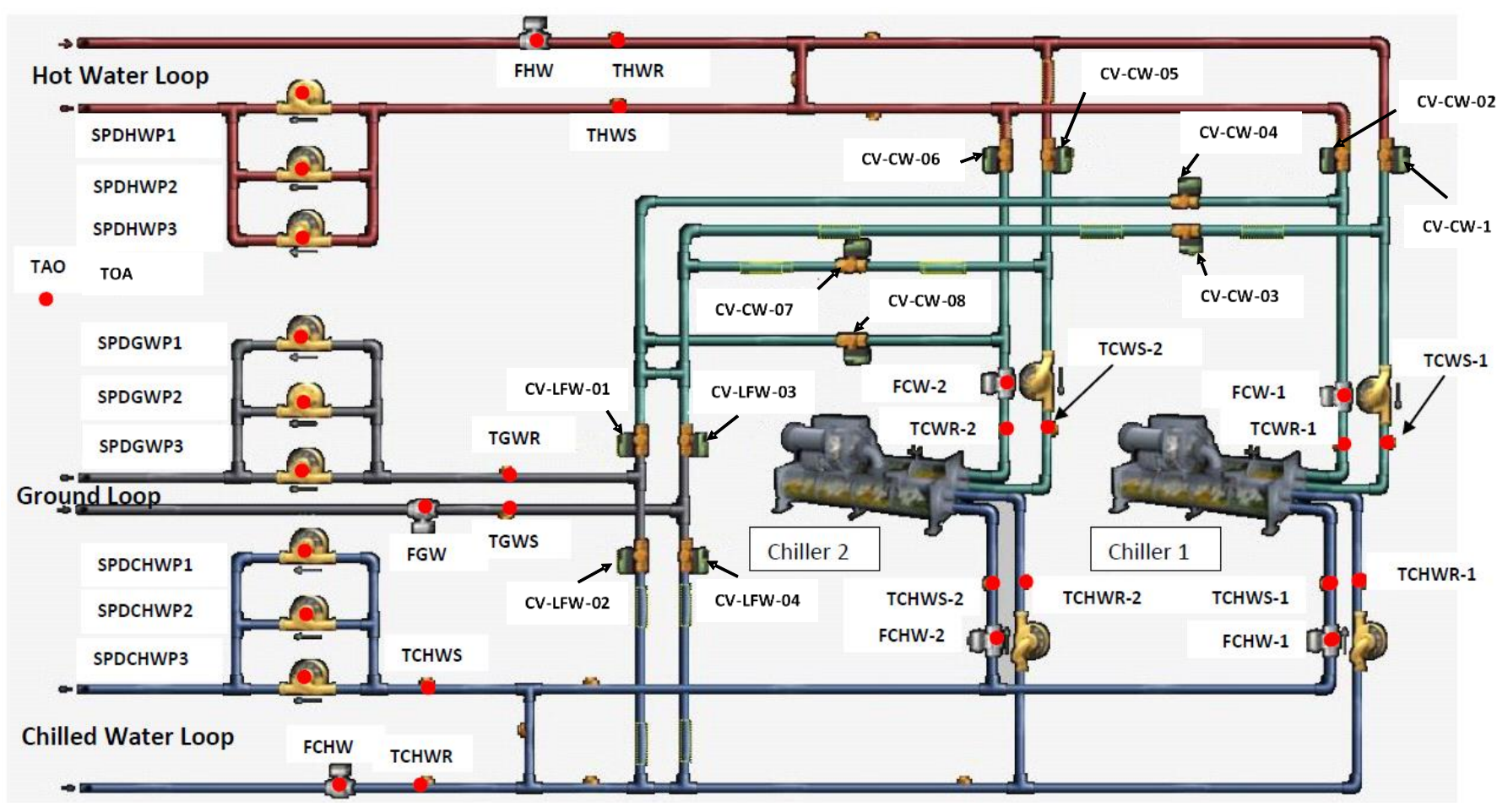

Figure 2. The schematic of the central GSHP system in DESN shown in BSU's Building Energy Management system (red dots indicating measured data)

Brief explanation of the acronyms used in the above schematic is given in following table:

\begin{tabular}{|l|l|l|l|}
\hline CV & Control valve & CW & Condenser water \\
\hline FCHW & Chilled water flow rate & FHW & Hot water flow rate \\
\hline FGW & Ground loop flow rate & TCHWR & Chilled water return temperature \\
\hline TCHWS & Chilled water supply temperature & THWR & Hot water return temperature \\
\hline THWS & Hot water supply temperature & TGWR & Ground loop return temperature \\
\hline TGWS & Ground loop supply temperature & SPDCHWP & single speed chilled water pump \\
\hline SPDHWP & single speed hot water pump & SPDGWP & single speed ground loop pump \\
\hline
\end{tabular}

Supplemental Heat Rejection. A fluid cooler (a wet cooling tower - not shown in Figure 2) was added to the ground loop in the spring of 2015 to reduce the excessively high ground loop temperatures experienced in the first a few years of operation.

\section{DATA ANAYLSIS RESULTS}

\section{Ground Loop Temperatures}

Error! Reference source not found. shows the monthly average supply and return temperatures of the geothermal borehole field (ground loop temperatures) and monthly average outdoor air temperature from August 2015 through July 2016. As shown in this figure, the difference between the monthly average supply and return temperatures during summer and winter ranged within $5-7^{\circ} \mathrm{F}\left(3-4^{\circ} \mathrm{C}\right)$ and $2-4^{\circ} \mathrm{F}\left(1-2^{\circ} \mathrm{C}\right)$, respectively. The ground loop temperatures in this period is lower than that one year ago (see Error! Reference source not found.). For example, 
the monthly average ground loop supply temperature during $2014-2015$ was 89 to $101^{\circ} \mathrm{F}$ ( 32 to $38^{\circ} \mathrm{C}$ ), while it ranged from 82 to $95^{\circ} \mathrm{F}\left(28\right.$ to $\left.35^{\circ} \mathrm{F}\right)$ in $2015-2016$. The decrease of the ground loop supply temperature is thought to be due to following reasons: (1) supplemental heat rejection through the fluid cooler, which was added to the ground loop in April 20152; and (2) more heating load in 2015-2016 as more buildings were connected to the campus-wide HW loop (see discussion in Heating and Cooling Outputs). The high ground loop temperature led to high heating efficiency of the HR chiller in winter but resulted in poor cooling efficiency in summer. Low heating loads and the sub-optimal operation of the HR chillers are thought to be the main reason of the high ground loop temperature. While the central GSHP system provided chilled water to most buildings in the campus, it took several phases to retrofit the existing heating systems in these buildings. As a result, the current heating load is lower than that when all the heating systems are retrofitted.

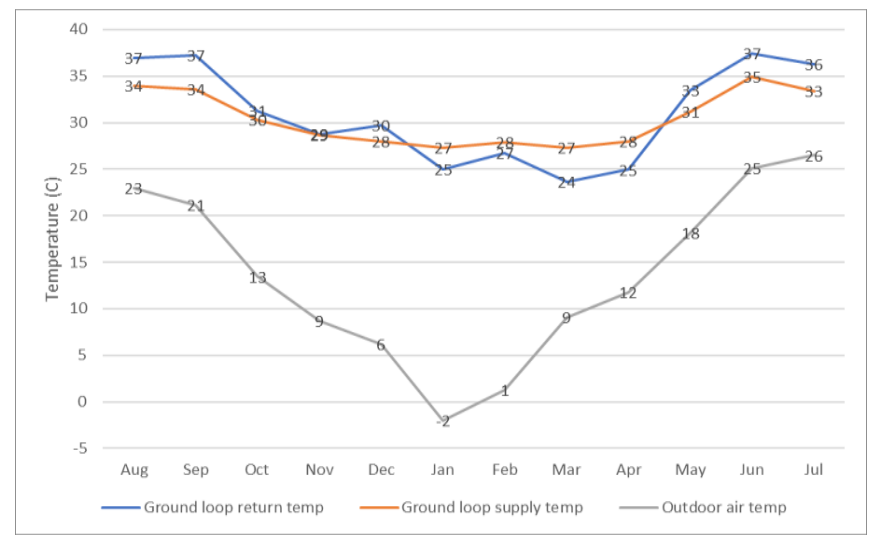

Figure 3. Monthly ground loop supply and return water temperatures at DESN and the outdoor air temperature (August 2015 through July 2016)

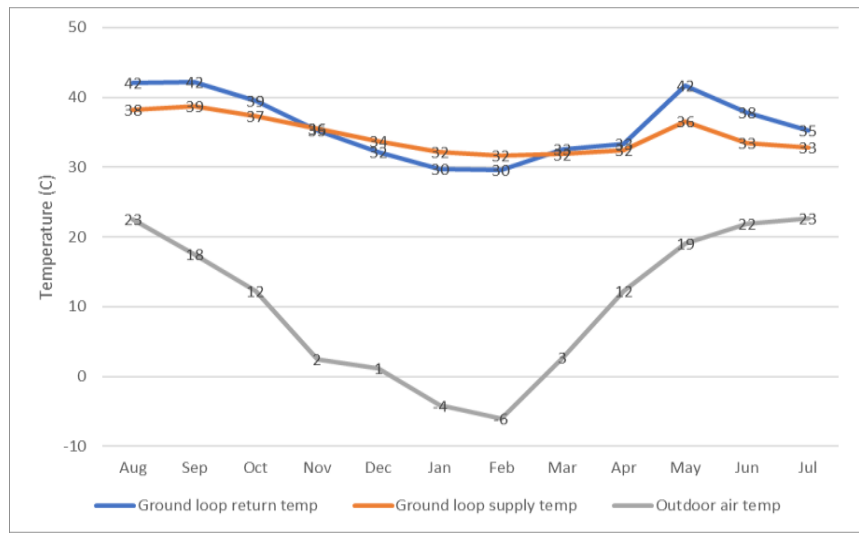

Figure 4. Monthly ground loop supply and return water temperatures at DESN and the outdoor air temperature (Previous year: August 2014 through July 2015)

\section{Heating and Cooling Outputs}

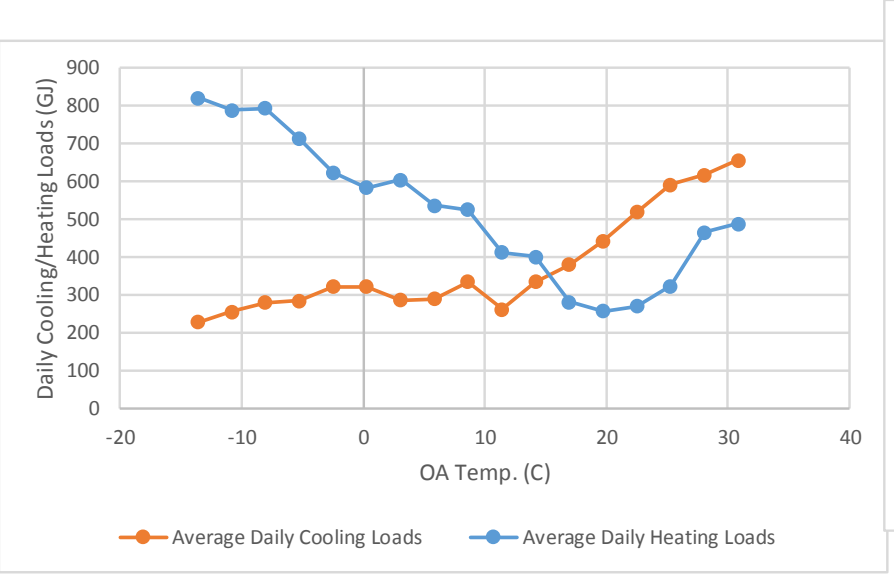

(a)

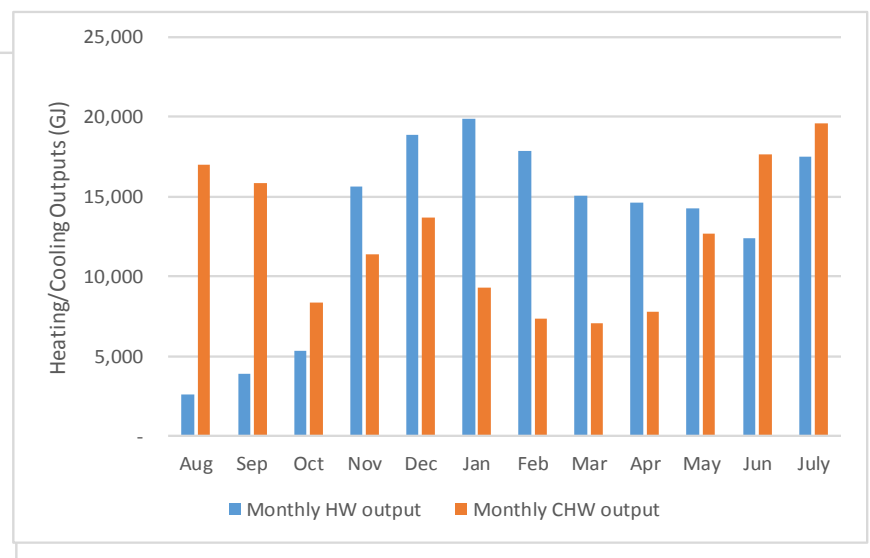

(b)

Figure 5 (a) shows the average daily heating and cooling energy provided by the GSHP system in DESN to the campus-wide CHW and HW loops. Each data point in this figure is the average of daily heating or cooling outputs

${ }^{2}$ Performance data of the fluid cooler were not measured, and the impact of the fluid cooer cannot be quantified. 
when the associated daily average outdoor air temperature is within a specific $5^{\circ} \mathrm{F}\left(2.8^{\circ} \mathrm{C}\right)$ bin (e.g., from $40-45^{\circ} \mathrm{F}$ or $4-$ $7^{\circ} \mathrm{C}$ ). The year-round cooling demands are due to high internal heat gains, which are typical in university buildings. The year-round heating demands are due to domestic hot water (DHW) preheating and reheating needs in variable air volume (VAV) HVAC systems, which are used in many buildings in the campus. Further investigation (Fig. 5b) reveals that the new GSHP system in DESN provided most HW to the campus in the summer of 2016 while it was the existing boilers in DESS that provided most HW in the summer of 2015. It resulted in an increase in the average daily heating loads when OA temperature was higher than $20^{\circ} \mathrm{C}$ as shown in Fig. 5(a). The total heating and cooling energy provided by the HR chillers in DESN was 149,738 MMBtu (157,988 GJ) and 140,032 MMBtu (147,747 GJ), respectively. During the same period in previous years (August 2014 through July 2015), the total heating and cooling energy was 79,124 MMBtu (83,483 GJ) and 108,065 MMBtu (114,019 GJ), respectively. It shows that there was a significant increase (i.e., about $89 \%$ ) in heating demand in 2015-2016.

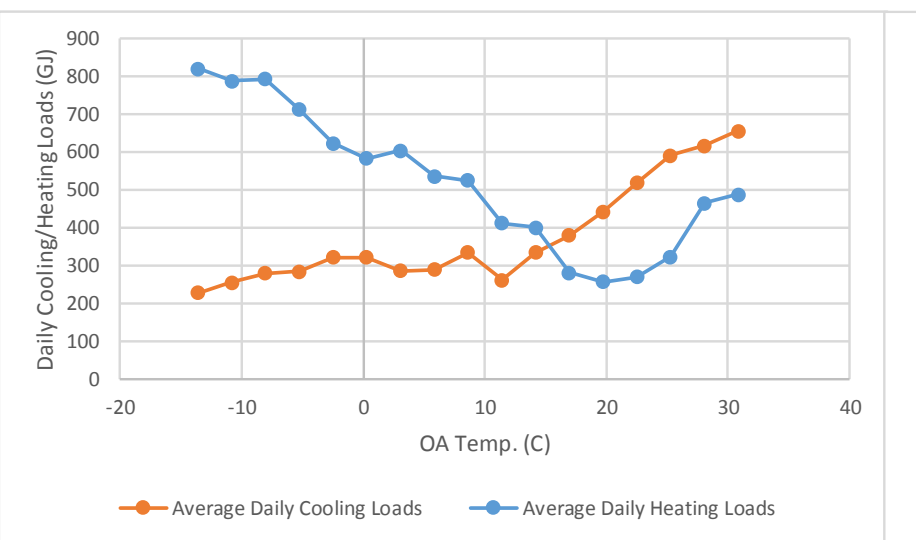

(a)

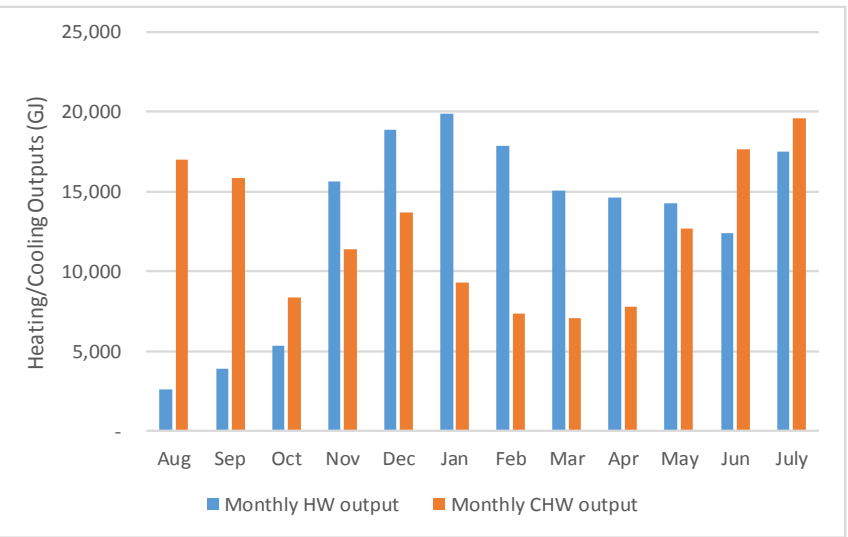

(b)

Figure 5. Heating and cooling outputs: (a)average daily at various outdoor air temperatures; and (b) monthly total

While the heating and cooling demands were balanced in 2015-2016, it was not the case for the heat extracted from and rejected to the ground. The annual heat rejection to and extraction from the ground were 71,684 MMBtu $(75,633 \mathrm{GJ})$ and $16,120 \mathrm{MMBtu}(17,008 \mathrm{GJ})$, respectively. The heat rejection to the ground is only about $52 \%$ of the total cooling outputs, and the heat extracted from the ground is only about $11 \%$ of the total heating output. Based on the heat balance of the chiller, the heat recovered from the condenser of the chiller (Q_HR) can be calculated with following Equation (1).

$$
\text { Q_HR = Q_clg + Q_clg/COP - Q_rej_GL }
$$

where, Q_HR is the heat recovered from the condenser of the chiller when it produces chilled water; Q_clg is the cooling output of the chiller; COP is the chiller cooling efficiency expressed as Coefficient of Performance; ; and Q_rej_GL is the heat rejected to the ground loop

The calculated annual Q_HR is 116,635 MMBtu (123,061 GJ), which is about 78\% of the annual heating output to the HW loop. While it is an expected benefit of the HR chiller, it may not be the optimal operation for the

${ }^{3}$ According to the HR chillers' catalog data, when it produces both $42^{\circ} \mathrm{F}\left(5.6^{\circ} \mathrm{C}\right)$ chilled water (from evaporator) and $125^{\circ} \mathrm{F}$ $\left(51.7^{\circ} \mathrm{C}\right.$ ) hot water (from condenser), the cooling COP is 2.9 . 
GSHP system. Since a large portion of the heating output is from the recovered heat at the condenser, the GSHP system did not extract much heat from the ground. As a result, the heat rejected to and extracted from the ground is significantly unbalanced even with the relatively balanced heating and cooling demands from the buildings. The significantly unbalanced thermal load of the ground is one of the reasons for the high ground loop temperature.

\section{Power Consumption}

Chillers' power consumption was measured continuously starting in August 2015. To verify the quality of the measured power consumption and other performance data of the chillers, the measured monthly chiller power consumption was compared with that calculated with other measured performance data using a heat balance equation (equations 2 and 3), and the analysis shows a close match between the calculated and the measured monthly chiller power consumption. It indicates good quality of the measured performance data.

$$
\begin{array}{ll}
\text { WCH1 } & \text { (Q_CW_1 - Q_CHW_1) } \\
\text { WCH2 } & =\text { (Q_CW_2 - Q_CHW_2) }
\end{array}
$$

where, WCH1 and WCH2 are the monthly power consumptions (in kWh) of chiller \#1 and \#2, respectively; Q_CW_1 and Q_CW_2 are the monthly condensing heat (in kWh) of chiller \#1 and \#2, respectively; and Q_CHW_1 and Q_CHW_2 are the monthly cooling outputs (in $\mathrm{kWh}$ ) at the evaporator of chiller \#1 and \#2, respectively.

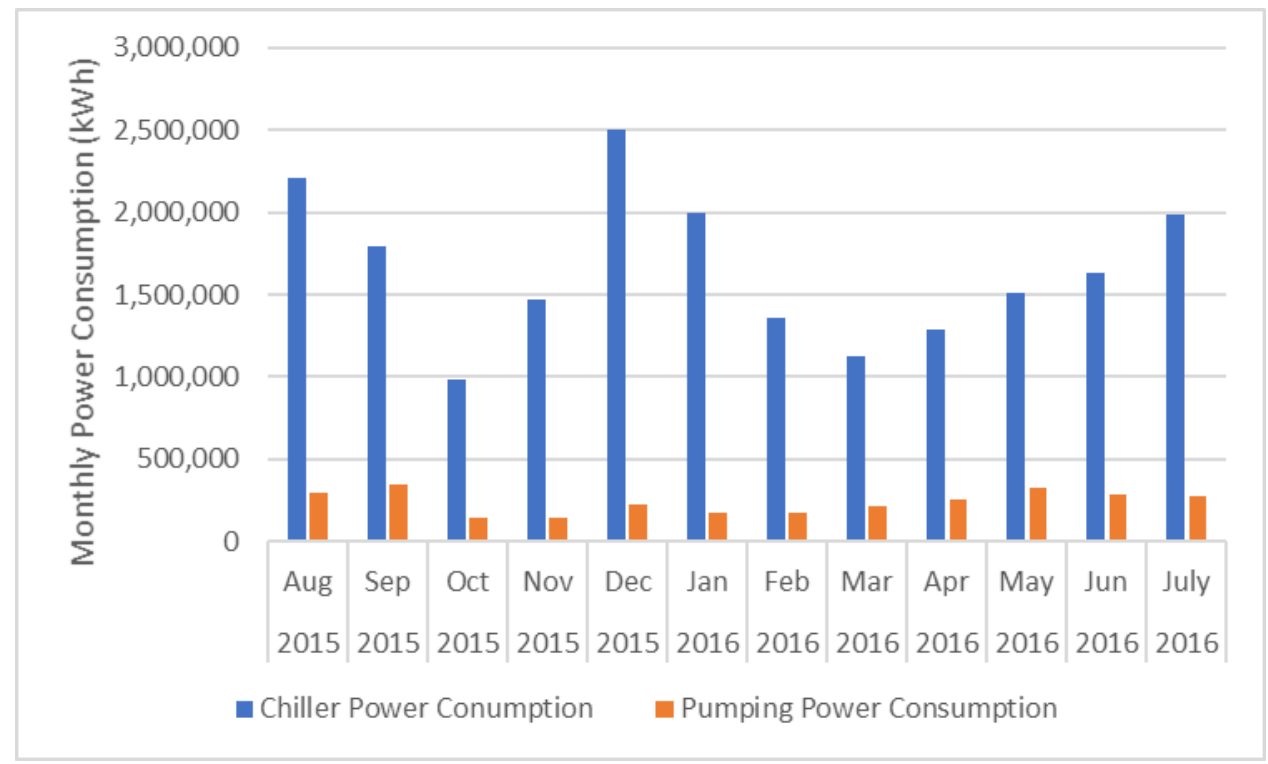

Figure 6. Monthly chiller power and pump consumption

Figure 6 shows the monthly chiller and pumping power consumption. The contribution of pumping power (excluding the tertiary pumps in each building) to the total GSHP system power consumption ranges from $8 \%$ to $18 \%$ at different months. On an annual basis, the pumping energy was $12.6 \%$ of the total power consumption of the district GSHP system at DESN.

\section{Energy Efficiency}

According to the HR chillers' catalog data, when it produces both $42^{\circ} \mathrm{F}\left(5.6^{\circ} \mathrm{C}\right)$ chilled water (from evaporator) and $125^{\circ} \mathrm{F}$ hot water (from condenser), they use $1.2 \mathrm{~kW}$ of power per each ton $(3.5 \mathrm{~kW})$ of cooling supplied, which is 
equivalent to a cooling COP of 2.9. With this efficiency, for each ton of cooling produced, there are 1.34 tons (4.7 kW) of heating available. The HR chiller could operate very efficiently (i.e., with an effective COP as high as 6.83) if both the produced chilled and hot water were fully used to satisfy the cooling and heating demands of the campus. However, if the produced CHW and HW are not fully used, and the surplus heating or cooling energy is thus dumped to the ground (as discussed before), the ECOP of the HR chiller is lower than the COP of conventional chiller or heat pump. Figure 7 shows ECOP of the HR chiller vs. the ratio of the daily HW demand (the heating output to the HW loop) to the daily CHW demand (the cooling output to the CHW loop). Each data point in this figure is the average of ECOPs within a 0.2 bin of the HW/CHW ratio. As shown, the minimum average daily ECOP of the HR chiller was about 2.5 when the HW/CHW ratio is less than 0.2 (i.e., most of the heating energy is dumped into the ground), and the ECOP was around 5 when the $\mathrm{HW} / \mathrm{CHW}$ ratio is near 1.3 (the ratio between the heating and cooling output of the HR chiller). The ECOP varied between 4 and 5 when the HW/CHW ratio is higher than 1.3, which means heating demand is much higher than the cooling demand. Based on measured annual cooling and heating outputs and the measured annual power consumption of the chiller, it is calculated that the annual average ECOP of the chiller was 4.28 \pm 0.2 . Accounting for annual pumping power consumption, the annual average ECOP of the district GSHP system at DESN was 3.74 \pm 0.2 . The \pm 0.2 uncertainty of ECOPs is calculated based on the accuracies of the sensors following the procedure described in ASHRAE Guideline 14-2014 - Measurement of Energy, Demand, and Water Savings (ASHRAE 2014).

The operational efficiency of the GSHP system could have been higher if the two chillers were operated separately - with one chiller always producing CHW, and the other operating as a heat pump to produce HW. Given the relatively balanced HW and CHW loads, these separate operations would reduce the ground loop temperature because (1) the (heat pump) chiller would produce only the needed HW necessary to satisfy the heating demand, eliminating dumping of $125^{\circ} \mathrm{F}\left(51.7^{\circ} \mathrm{C}\right) \mathrm{HW}$ into the ground loop; and (2) heat extraction from and heat rejection to the ground would be more balanced since the (heat pump) chiller would extract more heat from the ground. To satisfy the same heating and cooling demands, the two separately operated chillers using the ground loop as both heat source and heat sink would consume 17,806 MWh electricity. Compared with the electricity consumption of the asbuilt/operated GSHP system (19,853 MWh), the separate operations will save 2,047 MWh electricity. However, the separate operations will result in an increase in ground loop pumping energy use since more heat is extracted from and rejected to the ground loop. The calculation result indicates that the ground loop pumping energy use will increase by $715 \mathrm{MWh}$, so the net savings in electricity is $1,331 \mathrm{MWh}$, which is of $\$ 106,557$ value given the $\$ 0.08$ per $\mathrm{kWh}$ electricity rate. 


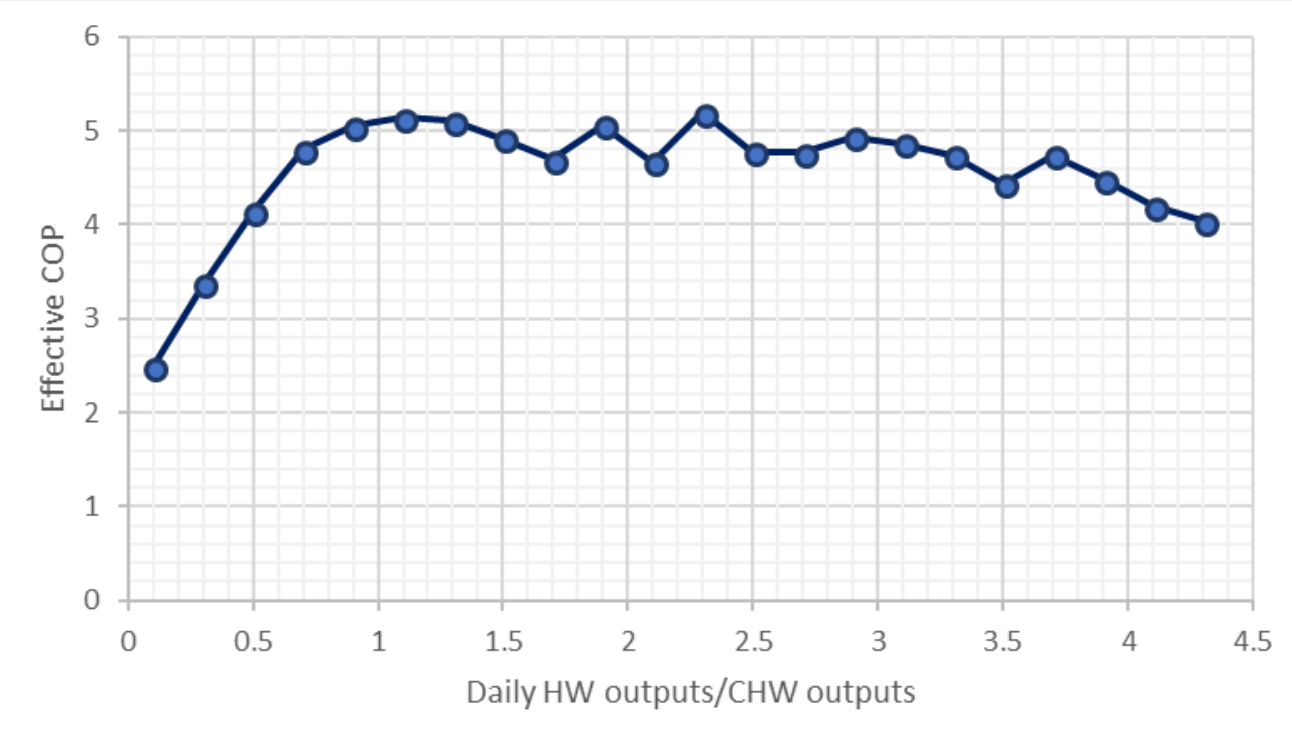

Figure 7: Average ECOP of the heat recovery chiller

\section{Energy Savings}

The energy savings achieved by the district GSHP system was determined by calculating the difference in measured energy consumptions between the GSHP system and the calculated energy consumption of a baseline HVAC system. The energy consumption of previous HVAC system in the campus was not sub-metered and thus can't be compared against. The baseline HVAC system includes a conventional water-cooled chiller and a natural gas boiler, which have the minimum energy efficiency as specified in ASHRAE Standard 90.1-2013 (ASHRAE 2013). The baseline chiller efficiency is $0.57 \mathrm{~kW} /$ ton $(\mathrm{COP}=6.1)$, and the boiler efficiency is $80 \%$. It was assumed that there are two 2,500-ton $(8,750 \mathrm{~kW})$ water-cooled centrifugal chillers, four 1,000-ton $(3,500 \mathrm{~kW})$ cooling towers, and three 20,000 $\mathrm{kBtu} / \mathrm{hr}(5,860 \mathrm{~kW})$ natural gas boilers. The baseline energy use was estimated using the measured cooling and heating outputs of the GSHP system, and a computer simulation of the centrifugal chillers and gas-fired boilers with DOE2/eQUEST (Hirsch 2016). Our calculation shows that the baseline HVAC system would consume 10,970 MWh electricity (including power consumptions of circulation pumps and a cooling tower) and 212,806 MMBtu (224,531 GJ) natural gas, respectively, in a year to provide the same heating and cooling outputs as the GSHP system. The source energy factor for delivered electricity is 3.443, which is an average value for U.S. Eastern Interconnection according to Deru and Tocellini (2007). The same literature also provides the $\mathrm{CO}_{2}$ emission factors for delivered electricity (i.e., $0.74 \mathrm{~kg}$ of pollutant per kWh of electricity) and natural gas (including $49.1 \mathrm{~kg}$ per GJ from on-site combustion and $4.6 \mathrm{~kg}$ per GJ from pre-combustion). These emission factors are used to calculate the $\mathrm{CO}_{2}$ emissions. The annual source energy savings achieved by the GSHP system is about 96,281 MMBtu (101,586 GJ), or a $27 \%$ reduction from the baseline source energy consumption. The annual energy cost savings is calculated based on the difference in annual energy consumption for electricity and natural gas between the simulated baseline HVAC system and the measured data of the district GSHP system. Assuming $\$ 0.08 / \mathrm{kWh}$ for electricity and $\$ 7.6 / \mathrm{GJ}$ for natural gas, the calculated annual energy cost savings is $\$ 764,200$ (a $30 \%$ savings compared with the baseline). In addition, the GSHP system has reduced $\mathrm{CO}_{2}$ emission by about $8,494,540 \mathrm{lbs}$ (3,853 ton) each year, which is a $19 \%$ reduction compared with the baseline system. More detailed information is presented in a technical report of this case study (Im et al. 2016).

\section{CONCLUSIONS AND LESSONS LEARNED}


- This case study indicates that the average system ECOP during the monitoring period was about 3.74, while the chiller ECOP is about 4.28. The monthly pumping power contribution to the total system power consumption ranges from $8 \%$ to $18 \%$.

- Compared with a baseline HVAC system with code-compliant efficiencies, the GSHP system in each year could avoid 101,586 GJ (a 27\% saving) source energy consumption, reduce 3,853 tons (a 19\% reduction) carbon emissions, and save $\$ 764,200$ (a 30\% saving) energy cost.

- The operational efficiency of the GSHP system could have been higher if the two chillers were operated separately — one chiller dedicates on producing chilled water, and the other chiller operates as a heat pump to produce only hot water. In this case, there is no need to dump the energy of the chilled or hot water to the ground. In addition, it will help balance the ground loop loads since more heat will be extracted from the ground to satisfy the heating demand.

\section{ACKNOWLEDGMENTS/DISCLAIMERS}

This manuscript has been coauthored by UT-Battelle, LLC under Contract No. DE-AC05-00OR22725 with the U.S. Department of Energy. The United States Government retains and the publisher, by accepting the article for publication, acknowledges that the United States Government retains a non-exclusive, paid-up, irrevocable, world-wide license to publish or reproduce the published form of this manuscript, or allow others to do so, for United States Government purposes.

\section{REFERENCES}

ASHRAE Standard 90.1-2013, Energy Standard for Buildings Except Low-Rise Residential Buildings, ASHRAE standard. ASHRAE Guideline 14-2014, Measurement of Energy, Demand, and Water Savings, ASHRAE standard.

Deru, M., and P. Tocellini. 2007. Source Energy and Emission Factors for Energy Use in Buildings, Technical Report, NREL/TP550-38617, National Renewable Energy Laboratory, Golden, Colorado.

Hirsch J. (2016). eQUEST program. www.doe2.com

Hughes, P. 2008. "Geothermal (Ground-Source) Heat Pumps: Market Status, Barriers to Adoption, and Actions to Overcome Barriers.” Rep. No. ORNL/TM-2008/232. Oak Ridge National Laboratory, Oak Ridge, TN. 